\title{
Influence of Preferences in Intervention Research: A Scoping Review
}

\author{
Review \\ Souraya Sidani ${ }^{1}$ \\ ${ }^{1}$ Daphne Cockwell School of Nursing, Ryerson University, Ryerson University, Toronto, Ontario, Canada.
}

Corresponding author: S. Sidani (ssidani@ryerson.ca)

\begin{abstract}
Introduction: Accounting for treatment preferences is beneficial in practice; it increases adherence to treatment and improves health outcomes. The randomized controlled trial (RCT) is considered the most robust in generating valid evidence on effectiveness, yet it ignores participants' preferences for treatment. This scoping review addresses three questions: 1) How are treatment preferences conceptualized in intervention research? 2) To what extent do treatment preferences affect participants' enrollment in trials, withdrawal from the study, adherence to treatment, and outcomes? and 3) What designs are used to account for treatment preferences in intervention evaluation research? Methods: The first five steps of the scoping review methodology framework were applied as follows: 1) identifying the research questions; 2) searching MEDLINE, CINAHL and PsychINFO; 3) selecting articles that evaluated interventions and accounted for preferences in the study design; 4) charting data on the definition and the influence of preferences on enrollment, attrition, and treatment adherence and outcomes; and 5) summarizing findings. Results: In total, 29 articles were included in the review. Treatment preferences refer to choice of treatment; they are shaped by participants' beliefs and appraisal of the interventions. Evidence from prior reviews and primary studies indicated that offering participants the opportunity to choose and receive the preferred treatment enhances enrollment and reduces withdrawal in trials; however, the evidence regarding the influence of treatment preferences on adherence to treatment and improvement in outcomes is inconclusive. Designs that account for treatment preferences include: RCT, RCT with a comprehensive cohort, partially randomized preference trial, and two-stage partially randomized trial. Conclusion: The results highlight the benefits of accounting for treatment preferences in enhancing enrollment and reducing attrition in intervention evaluation research, and the need for a systematic method for assessing preferences.
\end{abstract}

\section{KEYWORDS}

Enactment, enrollment, outcome, preferences, preference trials, withdrawal

\section{INTRODUCTION}

Person-centeredness is increasingly recognized as the core of high-quality healthcare in primary, acute, and long-term care settings (van Belle et al., 2020). The application of person-centeredness involves the engagement of persons in the identification and prioritization of their health problems, and in the treatment selection process (Wolf et al., 2017). The treatment selection process is collaborative, whereby healthcare providers inform people of alternative treatments or interventions for managing a health problem, discuss the benefits and risks of each intervention under consideration, explore the people's preferences for treatment, and provide the intervention of choice (Donovan et al., 2018; Sidani \&
Fox, 2014). Several benefits of accounting for treatment preferences have been reported in practice, including: enhanced people's experiences with healthcare, increased initiation and adherence to treatment, and improved health outcomes (Fors et al., 2018; Ren et al., 2019).

Intervention research is focused on demonstrating the effectiveness of interventions in preventing and/or managing health problems. The experimental or randomized controlled trial (RCT) design is considered the most robust or reliable in generating valid evidence on effectiveness (Holm et al., 2017). However, the experimental or RCT design ignores

115 
participants' preferences for treatment which, as reported previously, influence adherence to treatment and improvement in outcomes.

Preference trials have been introduced as an alternative (to the RCT) designs to account for participants' preferences in treatment allocation. Accounting for preferences is expected to enhance enrollment in trials, reduce attrition, and promote treatment adherence and outcomes (Bradley-Gilbride $\&$ Bradley, 2010). Although the use of preference trials is on the rise, there is limited clarity on the conceptualization of preferences and its impact on outcomes.

\section{PURPOSE}

This scoping review was conducted to generate an understanding of preferences and to summarize evidence on their influence on enrollment, withdrawal, and treatment adherence and outcomes. The findings can guide the design and evidence on the utility of preference trials in evaluating health interventions.

\section{METHODS}

A scoping review method was used because it is most suited for synthesizing available knowledge that addresses descriptive exploratory research questions. The first five steps of the scoping review method framework, originally outlined by Arksey and O'Malley (2005), and then refined by Colquhoun et al. (2014), were applied.

The first step consisted of identifying the research questions. This scoping review addressed the following questions:

(1) How are treatment preferences conceptualized in intervention research?

(2) To what extent do treatment preferences affect participants' enrollment in intervention evaluation studies or trials, withdrawal from the study, adherence to treatment, and achievement of beneficial outcomes?

IHTP, 1(1), 115-124, Spring 2021

CC BY-NC-ND 4.0
(3) What designs are used to account for treatment preferences in intervention evaluation research?

The second step involved the conduct of a literature search. The bibliographic databases, MEDLINE, CINAHL and PsychINFO, were searched using a combination of the following keywords: preferences, choice, treatment, intervention, therapy, and research or evaluation. The search was limited to peer-reviewed articles, published in English, from January 2010 to March 2020.

The third step entailed the selection of relevant articles. Articles were included if they reported on: 1) an intervention evaluation study, using randomized or preference-based methods for assigning participants to treatment; or 2) literature reviews (i.e., narrative, systematic, or meta-analytic) of studies or trials that investigated the impact of treatment preferences on participants' enrollment, withdrawal, adherence to treatment, and outcomes assessed at post-test. There were no restrictions on the type of interventions evaluated as well as on the population and setting.

The fourth step focused on data charting. A table was created to document the following data extracted from the selected articles: authors and year of publication (to describe the studies); conceptual and operational (i.e., measures) definitions of treatment preferences; factors shaping treatment preferences (to address the first research question); results reflecting the impact of treatment preferences (to address the second research question); and the design used (to address the third research question). The impact of treatment preferences was operationalized into: 1) enrollment rate, that is, the percentage of eligible participants who consented; 2) withdrawal rate, that is, the percentage of consenting participants who dropped out of the study; 3 ) adherence to treatment, that is, the percentage of participants who were engaged and enacted the treatment or who reported high attendance and compliance with the treatment recommendations; and 4) outcome, that is, the mean score on the respective outcome measure completed at post-test. The designs used were categorized into RCT or preference trials. The extent to which treatment preferences influenced enrollment, withdrawal, 
adherence, and outcomes was indicated by results showing differences between participants who: 1) were assigned to treatment randomly or by preference, or 2) did or did not receive an intervention that matched their preference.

\section{The fifth step involves summarizing and reporting} the findings.

\section{RESULTS}

The search yielded 41 articles. After initial review of the full articles, 12 were excluded because they either did not provide either a definition of preferences or results pertaining to the influence of preferences on enrollment, withdrawal, adherence, or outcomes. In total, 29 articles met the selection criteria. Ten articles were found that presented definitions of and discussed factors shaping treatment preferences. Relevant points were summarized and integrated into a conceptualization of treatment preferences. In total, 10 reviews and 9 primary studies reported on the impact of treatment preferences. The reviews included 3 narrative reviews, 4 systematic reviews, and 3 meta-analyses. The findings of the reviews and primary studies were synthesized to determine the influence of preferences on enrollment, withdrawal, adherence, and outcomes. Pertinent information was extracted from these reviews to describe designs used in evaluation research to account for treatment preferences. The findings of this scoping review are presented for each question.

\section{1) How are treatment preferences conceptualized?}

Treatment preferences refer to participants' choice of an intervention among alternative ones; that is, the preferred intervention is the one they want or desire to receive in order to address their health problem (Joy et al., 2013). Preferences are shaped by participants' beliefs and appraisal of the interventions under consideration (Clark et al., 2014).

Participants' beliefs reflect their etiological model, that is, their understanding of the health problem, its determinants and consequences, as well as their perspective on appropriate approaches and strategies to remedy the problem (Cohen et al., 2015). Participants' beliefs about the health problem emanate from their personal views and normative (e.g., cultural) beliefs about it, whereas their beliefs about remedial strategies are informed by their perspective on appropriate treatments as well as their awareness and experience with available treatments. Participants learn about available treatments from different sources such as the media, interactions with family and friends, and discussion with healthcare providers (Mills et al., 2011). Participants may have had personal or vicarious experience with specific treatments; that is, they may have actually applied an intervention or witnessed others' use of it. They may favor the intervention reported as successful in addressing the problem.

When presented with alternative interventions to manage a health problem, participants appraise them relative to a set of attributes they value. The attributes commonly reported of importance to participants include: 1 ) appropriateness in addressing the health problem, which reflects the degree to which an intervention is viewed as reasonable in managing the problem and is suitable to their life style and life circumstances; 2) potential effectiveness, which refers to the perceived usefulness of an intervention in addressing the problem; 3) perceived severity of the risks (i.e., adverse reactions or discomforts) that may be associated with an intervention; and 4) convenience, which is the extent to which an intervention is viewed as easy to apply and adhere to in their everyday life context (Harrison et al., 2014; Sidani et al., 2018; Witticke et al., 2012).

The general tendency is for participants to prefer treatments that are consistent with their beliefs and that are appraised as appropriate, effective, and convenient, with minimal risks (Kwan, Dimidjian \& Rizvi, 2010; Prody et al., 2013). For example, participants who believe that depression is due to biological factors (e.g., chemical imbalance) choose antidepressants over psychotherapy (Kemp, Lickel \& Deacon, 2014; Steidtmann et al., 2012). Medications that are consistent with their beliefs and viewed as appropriate and convenient, despite their potential risks or side effects.

Treatment preferences influence participants' engagement in intervention evaluation trials, through pathways that are elucidated in Sidani and Fox (2020). Briefly, participants with preferences for any 
treatment (experimental or comparison) under evaluation enroll in the trial. They are enthusiastic about the prospect of receiving the preferred treatment. However, in RCTs, participants may be randomized to the most or least preferred treatment. The match or mismatch between the preferred and the allocated treatment affects their subsequent behaviors. Those assigned to the treatment that matches their preference are motivated; they enact and adhere to treatment and therefore, experience the hypothesized improvement in the outcomes. In contrast, participants with mismatched treatment are disappointed. They may withdraw from the study to seek their preferred treatment outside the trial; alternatively, they continue their involvement in the study but do not initiate, enact, or adhere to treatment. Consequently, they experience less-thanoptimal or no improvement in the outcomes. Participants' enrollment and withdrawal may influence the trials' power to detect significant intervention effects and introduce potential confounding. Participants' level of adherence to treatment affects the estimates of the intervention's effects, leading to possible type I or type II error of inference regarding the success of the intervention in addressing the health problem (Sidani \& Fox, 2020).

\section{2) To what extent do treatment preferences affect enrollment, withdrawal, adherence and outcomes?}

The results of the reviews and the primary studies are summarized in Table 1, and synthesized below to address this question.

Impact of treatment preferences on enrollment: One review (Wasmann et al., 2019) and four primary studies (Chalmers et al., 2018; Kearny et al., 2011; Kwan et al., 2010; Mitchell-Jones et al., 2017) compared enrollment rates in studies or arms of trials in which participants were assigned to treatment either randomly or on the basis of their preferences. The results were consistent, showing higher enrollment rates when participants were aware of the preference-based method for treatment allocation and were actually offered the treatment of choice.

Impact of treatment preferences on withdrawal: Seven reviews examined the impact of treatment preferences on withdrawal, operationalized into attrition rates. Five reviews (Lindheim et al., 2014;
Prody et al., 2013; Swift, Callahan \& Vollmer, 2011; Swift et al., 2013; Wasmann et al., 2019) reported lower attrition rates in studies or arms of trials that provided treatment on the basis of preference, and/or among participants who received matched treatment. One review (Gelhorn, Sexton \& Classi, 2011) found no significant impact, whereas another review (Winter \& Barber, 2013) indicated inconsistent effects of preferences on attrition.

Impact of treatment preferences on adherence: One review and six primary studies investigated the influence of treatment preferences on adherence to treatment, which was operationalized as engagement or participation in the intervention activities, enactment of the treatment recommendations, and/or crossover to another intervention within the trial (reflecting non-adherence). The review (Gelhorn et al., 2011) and four primary studies (Cockayne et al., 2012; Floyd \& Moyer, 2010; Mitchell-Jones et al., 2017; Yancy et al., 2015) found no significant impact of providing the preferred treatment or receiving matched treatment on the rate or level of adherence. The results of two studies (Hubacher et al., 2017; Zoellner et al., 2019) showed increased engagement and/or enactment of treatment in participants with matched interventions.

Impact of treatment preferences on outcomes: Ten reviews examined the impact of treatment preferences on outcomes. Their results were mixed. The results of four reviews (Delvery \& Le, 2019; Lindheim et al., 2014; Swift et al., 2011; 2013) showed larger improvements in outcomes for participants allocated to their preferred treatment than those randomized to treatment. The effect sizes ranged between 0.15 and 0.31 . In contrast, four reviews (Gelhorn et al., 2011; Gemmell \& Dunn, 2011; Prody et al., 2013; Wasmann et al., 2019) found no significant impact of preferences on outcomes. In addition, two reviews (Franco et al., 2013; Winter \& Barber, 2013) reported inconsistent effects.

\section{3) What designs account for treatment preferences?}

Four designs have been used to examine the influence of treatment preferences in intervention research. Their main features, advantages and disadvantages are highlighted. 
RCT: In RCTs comparing two or more active treatments (i.e., excluding no-treatment control or placebo), participants are randomized to treatment. In addition, they are requested to indicate their preferences at baseline. Information on preferences is used to categorize participants as having received matched or mismatched treatment. The matchmismatch variable is included in the analysis to determine the extent to which it affects participants' withdrawal, adherence and outcomes. This design has the advantage of maintaining comparability of participants randomized to treatment groups, thereby minimizing possible confounding. However, assessing participants' preferences yet ignoring it with randomization, has been viewed as unethical (Sidani, 2015).

RCT with a comprehensive cohort: In this design, the plan is to randomize all participants to treatment. Participants who agree to randomization, are randomly assigned to treatment, as is done in the conventional RCT. Those who decline randomization form the comprehensive cohort and are given the opportunity to choose and receive the treatment they desire (Donovan et al., 2018). The advantage of this design is increased enrollment rates in the comprehensive cohort, and consequently the accrual of the required sample size. However, the number and the characteristics of participants in the comprehensive cohort may differ from those randomized, introducing potential confounding (Gemmell \& Dunn, 2011).

Partially randomized preference trial: This design is similar to the RCT with a comprehensive cohort design, except the pattern of assignment in that all participants are asked to indicate their preferences at baseline. Those with no preferences are randomized to treatment, whereas those with preferences are allocated to the treatment of choice. Although this design may enhance enrollment, reduce attrition, and improve treatment adherence and outcomes, it may result in differences between treatment groups on characteristics assessed at pretest, thereby introducing confounding.

Two-stage partially randomized or doubly randomized trial: This design was developed to mitigate the disadvantage of confounding that may be present with the partially randomized preference

IHTP, 1(1), 115-124, Spring 2021 CC BY-NC-ND 4.0 trial and the RCT with a comprehensive cohort. In the two-stage partially randomized trial, participants are randomized to the random arm or the preference arm of the trial. In the former arm, participants are randomly assigned to treatment, and in the latter arm, participants are allocated to the treatment of choice (Sidani, 2015).

\section{DISCUSSION}

The results of this scoping review clarified that treatment preferences are informed by participants' beliefs and appraisal of the interventions under evaluation. They highlight the increasing recognition of the role of preferences in intervention research, and the widening acceptance of trials that account for preferences in treatment allocation, as evidenced by the large number of studies and reviews included in this scoping review. Overall, the results indicate that offering participants the opportunity to choose and receive the preferred treatment enhances enrollment and reduces withdrawal in intervention evaluation studies. However, the evidence regarding the influence of treatment preferences on adherence to treatment and improvement in outcomes is inconclusive. The exact mechanism explaining this pattern of findings is not clear. It may be partially attributed to the methods used for eliciting participants' preferences.

In most studies included in this scoping review and in the selected reviews, the methods used for informing participants of the interventions under evaluation and for engaging them in the interventions' appraisal exercise are not described in detail. Further, preferences were assessed with one item asking participants to identify the treatment of choice (Wasmann et al., 2019). These less-thanoptimal methods may have contributed to illidentified or inaccurate preferences; that is, participants with limited understanding of the treatments and no opportunity to appraise the treatments for the attributes they value, could have hastily chosen a treatment. Nonetheless, participants appreciate the opportunity to choose treatment, and are enthusiastic about the prospect of receiving the desired treatment. Consequently, they decide to enroll and complete the evaluation study. However, with exposure and engagement in the treatment, participants may realize that the intervention they

119 
receive is not consistent with their beliefs and does not meet their expectations, that is, it is not suitable to their lifestyle and is burdensome. As a result, they may not adhere to the treatment and therefore, do not experience improvement in the outcomes (Mills et al., 2011).

Assessment of preferences should follow a systematic process, which involves three steps:

Step 1: Providing clear and comprehensive information on each intervention under evaluation. Participants need to understand each intervention's goals (what it is set to achieve), components and activities (what it consists of), mode and dose of delivery (how it is provided), benefits (how effective it is in addressing the health problem), and risks (what are potential discomforts or adverse reactions). The information is foundational for appraising the interventions (Sidani et al., 2018).

Step 2: Engaging participants in the interventions' appraisal exercise. Participants are requested to rate each intervention relative to four attributes: perceived appropriateness, effectiveness, risks, and convenience, prior to making a choice (Harrison et al., 2014). Different, easy to administer measures have been validated (e.g., Sidani \& Fox, 2020).

Step 3: Inquiring about participants' preferences. After appraising the interventions, participants are asked if they have a preference and which intervention they desire (Sidani et al., 2018).

\section{CONCLUSION}

Assessment of preferences and provision of treatments that are consistent with people's preferences are essential elements of personcentered care. Accounting for preferences in intervention evaluation research is useful to enhance recruitment and enrollment, and reduce withdrawal, which are both required to accrue the required sample size and maintain adequate statistical power of the trial. Accounting for preferences also generates evidence of relevance to practice, further supporting the benefits of the person-centered approach to care. To demonstrate the utility of assigning or providing the treatment of preferences in research and practice, a systematic method for assessing preferences should be applied.

IHTP, 1(1), 115-124, Spring 2021 CC BY-NC-ND 4.0

\section{REFERENCES}

Arksey, H., \& O'Malley, L. (2005). Scoping studies: Towards a methodological framework. International Journal of Social Research Methodology: Theory and Practice, 8 (1), 1932.https://doi.org/10.1080/1364557032000 119616.

Bradley-Gilbride, J. \& Bradley, C. (2010). Partially randomized preference trial design. In N.J. Salkind (Ed), Encyclopedia of research design. USA: Sage, Vol 2, 1009-1015.

Chalmers, J.A., Sansom-Daly, U.M., Patterson, P., McCowage, G. \& Anazodo, A. (2018). Psychosocial assessment using telehealth in adolescents and young adults with cancer: A partially randomized patient preference pilot study. Journal of Medical Internet Research,7(8),e168.doi:10.2196/resprot.88 86.

Clark, M.D., Determann, D., Petrou, S., Moro, D. \& de Bekker-Grob, E. W. (2014). Discrete choice experiments in health economics: A review of the literature. Pharmaco Economics, 32, 883-902.

Cockayne, S., Hicks, K., Kangombe, A.R., Hewitt, C., Concannon, M., Thomas, K., Hashmi, F., McIntosh, C., Brierley, G., Torgerson, D. \& Watt, I., On behalf of the EVerT team (2012). The effect of patients' preference on outcome in the EVerT cryotherapy versus salicylic acid for the treatment of plantar warts (verruca) trial. Journal of Foot and Ankle Research, 5, 28 - 34. http://www.jfootankleres.com/content/5/1 /28.

Cohen, J.N., Potter, C.M., Drabick, D.A.G., Blanco, C., Schneider, F.R., Liebowitz, M.R. \& Heimberg, R.G. (2015). Clinical presentation and pharmacotherapy response in social anxiety disorder: the effect of etiological beliefs. Psychiatry Research, 28 (1), 65-71. doi: 10.1016/j.psychres.2015.04.014.

Colquhoun, H. L., Levac, D., O’Brien, K. K., Straus, S., Tricco, A. C., Perrier, L., Kastner, M. \& Moher, D. (2014). Scoping reviews: Time for clarity in definition, methods, and reporting. Journal of Clinical Epidemiology, 67 (12), 1291-1294. 
https://doi.org/10.1016/i.jclinepi.2014.03.0 13.

Delevry, D. \& Le, Q.A. (2019). Effect of treatment preference in randomized controlled trials: systematic review of the literature and meta-analysis. The Patient - PatientCentered Outcomes Research, 12, 593-609. https://doi.org/10.1007/s40271-019-003796.

Donovan, J.L., Young, G.J., Walsh, E.I., Metcalfe, C., Lane, J.A., Martin, R.M., Tazewell, M.K., Davis, M., Peters, T.J., Turner, E.L., Mills, N., Khazraghi, H., Khera, T.K., Neal, D.E., Hamdy, F.C., ProtecT Study Group (2018). A prospective cohort and extended comprehensive-cohort design provided insights about the generalizability of a pragmatic trial: The ProtecT prostate cancer trial. Journal of Clinical Epidemiology, 96, 3546. doi: 10.1015/j.jclinepi.2-17.12.019.

Floyd, A.H.L. \& Moyer, A. (2010). Effects of participant preferences in unblinded randomized controlled trials. Journal of Empirical Research on Human Research Ethics: An International Journal, 5 (2), 81-93. doi: 10.1525/jer.2010.5.2.81.

Franco, M.R., Ferreira, M.L., Ferreira, P.H., Maher, C.G., Pinto, R.Z. \& Cherkin, D.C. (2013). Methodological limitations prevent definitive conclusions on the effects of patients' preferences in randomized clinical trials evaluating musculoskeletal conditions. Journal of Clinical Epidemiology, 66, 586598. doi: 10.1016/j.jclinepi.2012.12.012.

Fors, A., Blanck, E., Ali, L., Ekberg-Jansson, A., Fu, M., Lindström Kjellberg, I., Mäkitalo, $\AA$., Swedberg, K., Taft, C. \& Ekman, I. (2018). Effects of a person-centered telephonesupport in patients with chronic obstructive pulmonary disease and/or chronic heart failure $-\mathrm{A}$ randomized controlled trial. PLOS ONE, 13 (8), e0203031.

Gelhorn, H.L., Sexton, C.C. \& Classi, P.M. (2011). Patient preferences for treatment of major depressive disorder and the impact on health outcomes: A systematic review. Primary Care Companion for CNS Disorders, 13 (5). doi: 10.4088/PCC.11r01161.

Gemmell, I. \& Dunn, G. (2011). The statistical pitfalls of the partially randomized preference design in non-blinded trials of psychological interventions. International Journal of Methods in Psychiatric Research, 20 (1), 1-9. doi: 10.1102/mpr.326.

Harrison, M., Rigby, D., Vass, C., Flynn, T., Louviere, J., \& Payne, K. (2014). Risk as an attribute in discrete choice experiments: A systematic review of the literature. Patient, 7, 151-170.

Holm, M., Alvariza, A., Fürst, C-J., Wengström, Y., Årestedt, K., Öhlen, J. \& Goliath, I. (2017). Recruiting participants in a randomized controlled trial testing an intervention in palliative cancer care - The perspectives of health care professionals. European Journal of Oncology Nursing, 31, 6-11. https://doi.org/10/1016/j.ejon2017.09.001.

Hubacher, D., Spector, H., Monteith, C., Chen, P.L. \& Hart, C. (2017). Long-acting reversible contraceptive acceptability and unintended pregnancy among women presenting for short-acting methods: a randomized patient preference trial. American Journal of Obstetrics \& Gynecology, 216, 101-109. https://doi.org/10.1016/j.ajog.2016.08.033, 10.1016/j.ajog.2016.08.033.

Joy, S.M., Little, E., Maruthur, N.M., Purnell, T.S. \& Bridges, J.F.P. (2013) Patient preferences for the treatment of type 2 diabetes: A scoping review. Pharmaco Economics, 31, 877-892.

Kearney, R.S., Achten, J., Parsons, N.R. \& Costa, M.L. (2011). The comprehensive cohort model in a pilot trial in orthopaedic trauma. BMC Medical Research Methodology, 11, 39. doi:10.1186/1471-2288-11-39.

Kemp, J.J., Lickel, J.J. \& Deacon, B.J. (2014). Effects of a chemical imbalance causal explanation on individuals' perceptions of their depressive symptoms. Behaviour Research \& Therapy, 56, 47-51. doi: 10.1016/j.brat.2014.02.009.

Kwan, B.M., Dimidjian, S. \& Rizvi, S.L. (2010) Treatment preferences, engagement, and clinical improvement in pharmacotherapy versus psychotherapy for depression. Behavior Research \& Therapy, 48, 799-804.

Lindheim, O., Bennett, O., Trentacosta, C.J. \& McLear, C. (2014). Client preferences affect treatment satisfaction, completion and clinical outcome: A meta-analysis. Clinical Psychology Review, 34, 506-517. 
Mills, N., Donovan, J.L., Wade, J., Hamdy, F.C., Neal, D.E. \& Lane, J.A. (2011). Exploring treatment preferences facilitated recruitment to randomized controlled trials. Journal of Clinical Epidemiology, 64, 1127-1136. doi: 10.1016/j.jclinepi.2010.12.017.

Mitchell-Jones, N., Farren, J.A., Tobias, A., Bourne, T. \& Bottomley, C. (2017). Ambulatory versus inpatient management of severe nausea and vomiting of pregnancy: a randomised control trial with patient preference arm. BMJ Open, 7, e017566. doi: 10.1136/bmjopen-2017017566.

Prody, S.L., Burch, J., Crouch, S. \& MacPherson, H. (2013). Insufficient evidence to determine the impact of patient preferences on clinical outcomes in acupuncture trials: A systematic review. Journal of Clinical Epidemiology, 66, 308-318.doi: 10.1016/j.jclinepi.2012.09.011.

Ren, J., Li, Q., Zhang, T., Li, X., Zhang, S., Wright, J., Liu, H. \& Hua, Z. (2019). Perceptions of engagement in health care among patients with tuberculosis: a qualitative study. Patient Reference and Adherence, 13, 107117.

Sidani, S. (2015) Health intervention research: Advances in research design and methods. London, UK: Sage.

Sidani, S. \& Fox, M. (2020). The role of treatment perceptions in intervention evaluation: A review. Science of Nursing and Health Practices, 3 (2) Article 4. Article 1079.

Sidani, S. \& Fox, M. (2014). Patient-centered care: A clarification of its active ingredients. Journal of Interprofessional Care, 28 (2), 134-141. doi: 10.3109/13561820.2013.86519.

Sidani, S., Epstein, D.R., Miranda, J. \& Fox, M. (2018). Psychometric properties of the Treatment Perception and Preferences scale. Clinical Nursing Research, 27 (6), 743-761. doi: 10.1177/1054773816654137.

Steidtmann, D., Manber, R., Arnow, B.A., Klein, D.N., Markowitz, J.C., Rothbaum, B.O., Thase, M.E. \& Kocsis, J.H. (2012). Patient treatment preference as a predictor of response and attrition in treatment for chronic depression. Depression \& Anxiety, 29, 896-905.

Swift, J.K., Callahan, J.L. Ivanovic, L.M. \& Kominiak, N. (2013). Further examination of the psychotherapy preference effect: A meta- regression analysis. Journal of Psychotherapy Integration, 23 (2), 134-145. doi: $10.1037 / \mathrm{a} 0031423$.

Swift, J.K., Callahan, J.L. \& Vollmer, B.M. (2011) Preferences. Journal of Clinical Psychology: In Session, 67 (2), 155-165.

Van Belle, E., Giesen, J., Conroy, T., Van Mierlo, M., Vermeulen, H., Huisman-de Waal G, \& Heine, M. (2020). Exploring person-centred fundamental nursing care in hospital wards: A multi-site ethnography. Journal of Clinical Nursing, 29 (11-12):1933-1944. doi: 10.1111/jocn.15024.

Wasmann, K., Wijsman, P., van Dieren, S., Bemelman, W. \& Buskens, C. (2019). Influence of patients' preference in randomised controlled trials. Journal of Crohn's and Colitis, 13 (Issue Suppl - 1), S517-S518. doi: 10.1093/ecco-jcc/jjy222.915.

Winter, S. E., \& Barber, J.P. (2013). Should treatment for depression be based more on patient preference? Patient Preference and Adherence, 7, 1047-1057.

Witticke, D., Seidling, H.M., Klimm, H-D. \& Haefeli, W.E. (2012). Do we prescribe what patients prefer? Pilot study to assess patient preferences for medication regimen characteristics. Patient Preference \& Adherence, 6, 679-684.

Wolf, A., Moore, L., Lydahl, D., Naldemirci, Ö., Elam, M. \& Britten, N. (2017). The realities of partnerships in person-centered care: a qualitative interview study with patients and professionals. BMJ Open, 7, e016491.

Yancy et al., 2015) Yancy, W.S., Mayer, S.B., Coffman, C.J., Smith, V.A., Kolotkin, R.L., Geiselman, P.J., McVay, M.A., Oddone, E.Z. \& Voils, C.I. (2015). Effect of Allowing Choice of Diet on Weight Loss. A Randomized Trial. Annals of Internal Medicine, 162 (12), 805-814. doi:10.7326/M14-2358.

Zoellner, L.A., Roy-Byrne, P.P., Mavissakalian, M. \& Feeny, N.C. (2019). Doubly randomized preference trial of prolonged exposure versus sertraline for treatment of PTSD. American Journal of Psychiatry, 176, 287296. https://doi.org/10.1176/appi.ajp.2018.1709 0995. 
Table 1: Summary of findings reported in 10 reviews and 9 primary studies

\begin{tabular}{|c|c|c|c|}
\hline Author & Design & Interventions & Findings \\
\hline \multicolumn{4}{|l|}{ REVIEWS } \\
\hline Delevry et al. (2019) & Meta-analysis & varied & $\begin{array}{l}\text { Effect on outcome (mean ES = } 0.18 \text { overall, } 0.23 \text { for mental } \\
\text { health outcomes) }\end{array}$ \\
\hline Franco et al. (2013) & $\begin{array}{l}\text { Systematic } \\
\text { review }\end{array}$ & varied & Effect on outcome (inconsistent) \\
\hline Gelhorn et al. (2011) & $\begin{array}{l}\text { Narrative } \\
\text { review }\end{array}$ & $\begin{array}{l}\text { Pharmacotherapy, } \\
\text { Psychotherapy }\end{array}$ & $\begin{array}{l}\text { No effect on attrition } \\
\uparrow \text { engagement in treatment } \\
\text { No effect on enactment of treatment } \\
\text { No effect on outcome }\end{array}$ \\
\hline Gemmell \& Dunn (2011) & $\begin{array}{l}\text { Narrative } \\
\text { review }\end{array}$ & varied & No effect on outcome \\
\hline Lindheim et al. (2014) & $\begin{array}{l}\text { Systematic } \\
\text { review }\end{array}$ & varied & $\begin{array}{l}\downarrow \text { attrition }(\mathrm{OR}=1.37) \\
\text { Effect on outcome }(\mathrm{ES}=0.15 \text { ) }\end{array}$ \\
\hline Prody et al. (2013) & $\begin{array}{l}\text { Systematic } \\
\text { review }\end{array}$ & Acupuncture & $\begin{array}{l}\downarrow \text { attrition } \\
\text { No effect on outcome }\end{array}$ \\
\hline Swift et al. (2011) & Meta-analysis & $\begin{array}{l}\text { Pharmacotherapy, } \\
\text { Psychotherapy }\end{array}$ & $\begin{array}{l}\downarrow \text { attrition (OR }=0.59) \\
\text { Effect on outcome }(E S=.31 \text { ) }\end{array}$ \\
\hline Swift et al. (2013) & Meta-analysis & Psychotherapy & $\begin{array}{l}\downarrow \text { attrition } \\
\text { Effect on outcome (small) }\end{array}$ \\
\hline Wasmann et al. (2019) & $\begin{array}{l}\text { Systematic } \\
\text { review }\end{array}$ & varied & $\begin{array}{l}\uparrow \text { enrollment } \\
\downarrow \text { attrition } \\
\text { No effect on outcome }(E S=0.09)\end{array}$ \\
\hline Winter \& Barber (2013) & $\begin{array}{l}\text { Narrative } \\
\text { review }\end{array}$ & Psychotherapy & $\begin{array}{l}\text { Effect on attrition (inconsistent) } \\
\text { Effect on engagement in treatment (inconsistent) } \\
\text { Effect on outcome (inconsistent) }\end{array}$ \\
\hline \multicolumn{4}{|l|}{ PRIMARY STUDIES } \\
\hline Chalmers et al. (2018) & $\begin{array}{l}\text { Partially } \\
\text { randomized } \\
\text { preference trial }\end{array}$ & $\begin{array}{l}\text { Different modes } \\
\text { for delivering } \\
\text { psycho-social } \\
\text { assessment }\end{array}$ & $\uparrow$ enrollment rate \\
\hline Cockayne et al. (2012) & $\begin{array}{l}\mathrm{RCT}+ \\
\text { comprehensive } \\
\text { cohort }\end{array}$ & $\begin{array}{l}\text { Cryotherapy, } \\
\text { Salisylic acid }\end{array}$ & $\begin{array}{l}\text { No effect on attrition } \\
\text { No effect on engagement in treatment } \\
\text { No effect on enactment or adherence to treatment } \\
\text { No effect on outcome }\end{array}$ \\
\hline Floyd \& Moyer (2010) & $\mathrm{RCT}$ & Music & No effect on adherence \\
\hline
\end{tabular}




\begin{tabular}{|c|c|c|c|}
\hline Hubacher et al. (2017) & $\begin{array}{l}\text { Partially } \\
\text { randomized } \\
\text { preference trial }\end{array}$ & $\begin{array}{l}\text { Short or long } \\
\text { acting }\end{array}$ & $\begin{array}{l}\uparrow \text { enactment of treatment } \\
\text { Effect on outcome (small) }\end{array}$ \\
\hline Kearney et al. (2011) & $\begin{array}{l}\mathrm{RCT}+ \\
\text { comprehensive } \\
\text { cohort }\end{array}$ & Rehabilitation & $\begin{array}{l}\uparrow \text { enrollment } \\
\text { No effect on outcome }\end{array}$ \\
\hline Kwan et al. (2010) & RCT & $\begin{array}{l}\text { Pharmacotherapy, } \\
\text { Behaviour }\end{array}$ & $\begin{array}{l}\uparrow \text { enrollment } \\
\downarrow \text { attrition } \\
\uparrow \text { engagement in treatment } \\
\text { No direct effect on outcome } \\
\text { Indirect effect on outcome, mediated by engagement in } \\
\text { treatment }\end{array}$ \\
\hline $\begin{array}{l}\text { Mitchell-Jones et al. } \\
\text { (2017) }\end{array}$ & $\begin{array}{l}\mathrm{RCT}+ \\
\text { comprehensive } \\
\text { cohort }\end{array}$ & $\begin{array}{l}\text { Ambulatory vs } \\
\text { inpatient } \\
\text { management }\end{array}$ & $\begin{array}{l}\uparrow \text { enrollment } \\
\text { No effect on attrition } \\
\text { No effect on engagement and enactment of treatment } \\
\text { No effect on outcome }\end{array}$ \\
\hline Yancy et al. (2015) & $\begin{array}{l}\text { Two-stage } \\
\text { partially } \\
\text { randomized } \\
\text { trial }\end{array}$ & Diet types & $\begin{array}{l}\text { No effect on attrition } \\
\text { No effect on engagement in treatment } \\
\text { No effect on enactment of treatment } \\
\text { No effect on outcome }\end{array}$ \\
\hline Zoellner et al. (2019) & $\begin{array}{l}\text { Two-stage } \\
\text { partially } \\
\text { randomized } \\
\text { trial }\end{array}$ & $\begin{array}{l}\text { Pharmacotherapy, } \\
\text { Psychotherapy }\end{array}$ & $\begin{array}{l}\uparrow \text { enactment of treatment } \\
\text { Effect on outcome (ES: } 0.40 \text { to } 0.72 \text { ) }\end{array}$ \\
\hline
\end{tabular}

